


\section{الصورة الفنية في شعر أبـ مدين الغوث}

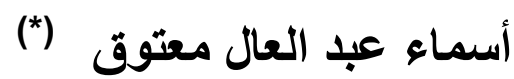

الصورة الفنية هي أساس البناء الثعرى، والخيال هو منبع الثـاعر الذى لئى

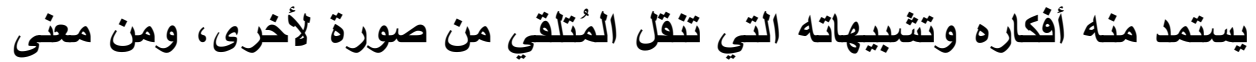

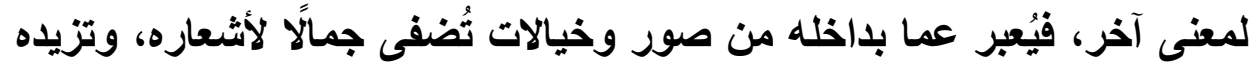

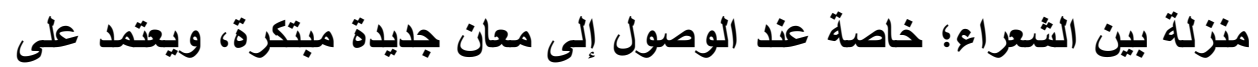

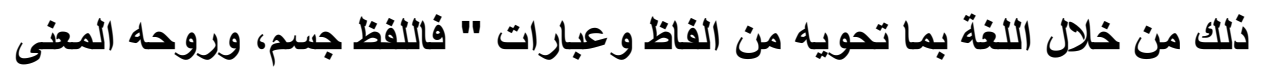

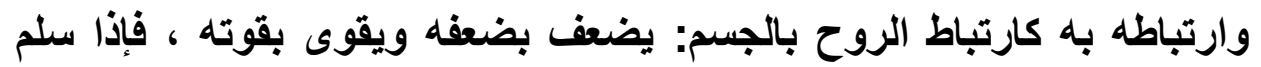

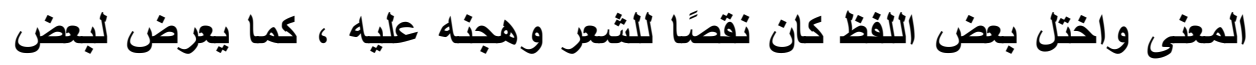

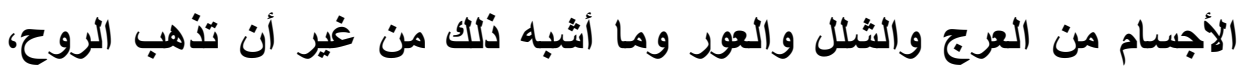

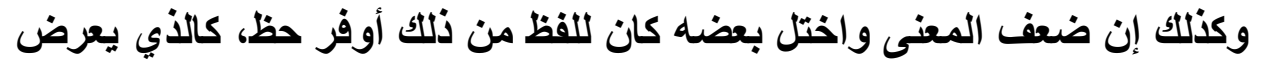

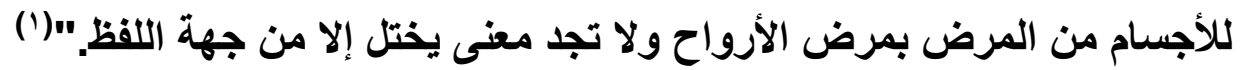

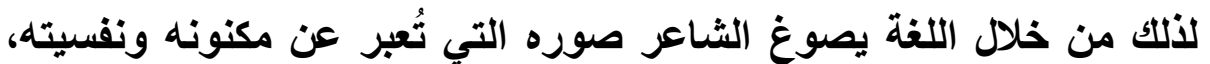

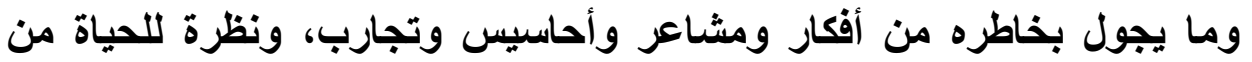
منظاره الخاص، حيث إن " الصياغة والأسلوب بطريقة الأداء أو طريقة التعبير التي يسلكها الأديب؛ لتصوير ما في نفسه أو لنقله إلى سواه بهذه العاء العبارات

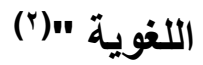

\section{التشبيه}

يعد التشبيه وسيلة من وسائل التعبير البياني وهو أقربها إلى الفهم، حيث

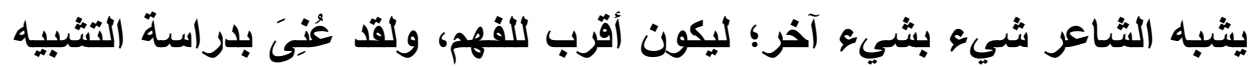

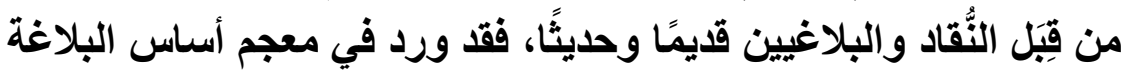

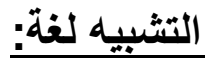

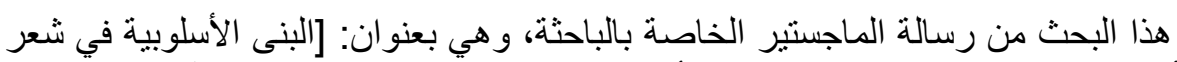

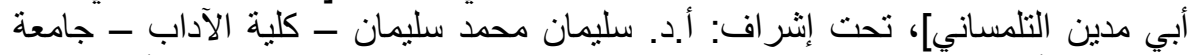

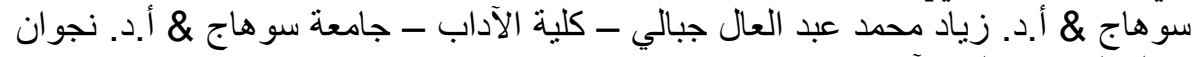

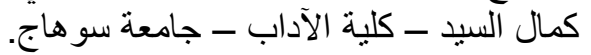

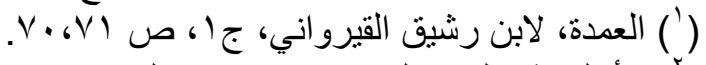

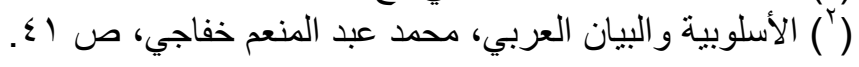




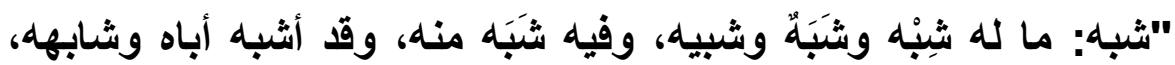

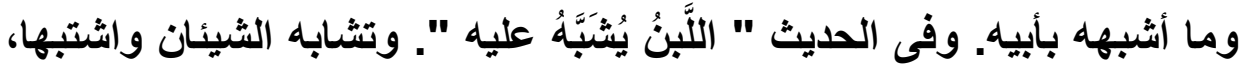

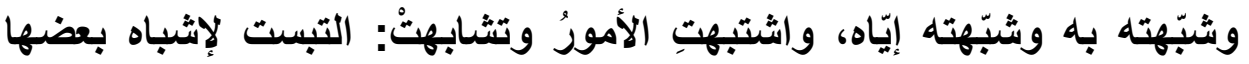

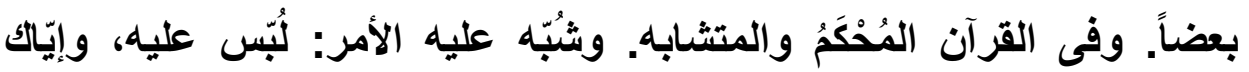

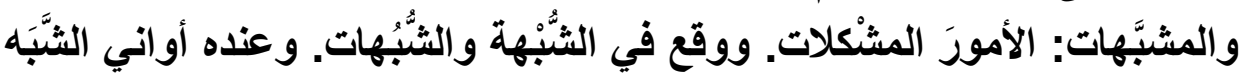

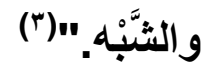

التشبيه اصطلاحا: ولئه

" صفة الشيع بما قاربه وشاكله، ومن جهة واحدة أو جهات كثيرة لا من

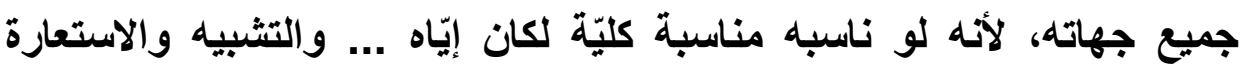

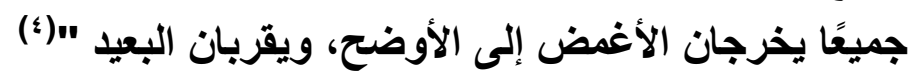

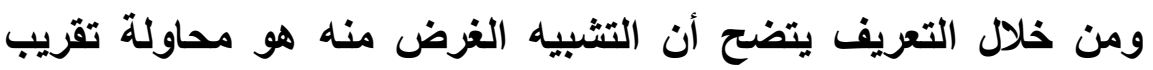
صورة من صورة أخرى؛ لكشف الغموض إذ هو " تقريب المشبه من فهم أنه

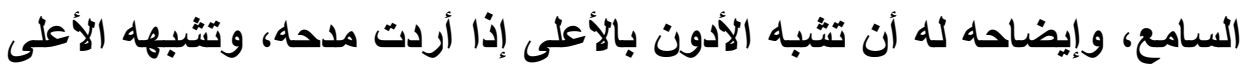

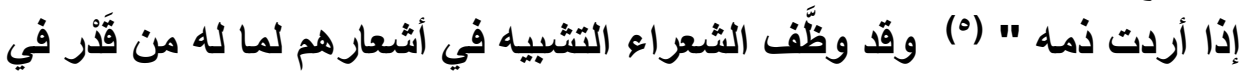
إثراء القصيدة وقوة أبياتها.

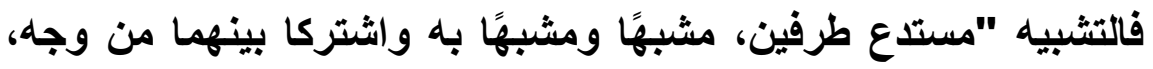

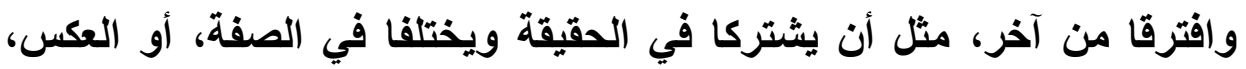

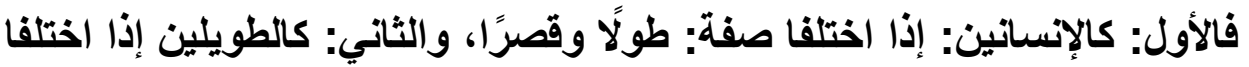

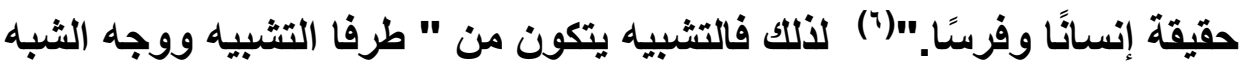
والغزض في التشبيه وأحوال التشبيه، ككونه: قريبًا أو غرييًا، مقبولًا أو

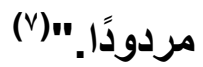
أدوات التشبيه: - n مدود

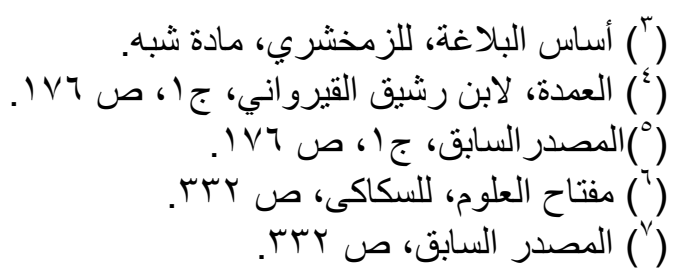


للتشبيه أدوات يُعرف بها " أصل التشبيه مع دخول الكاف وأمثالها أو كأن

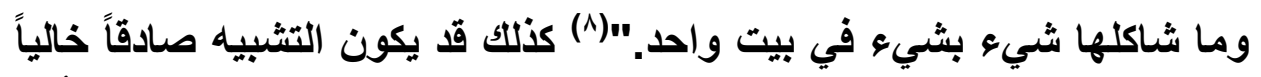

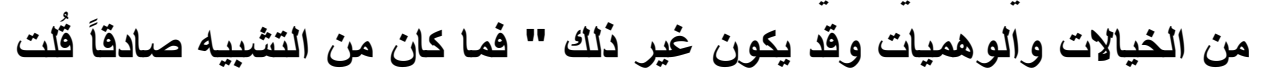

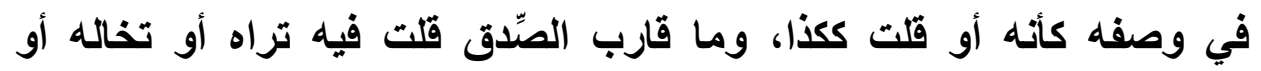
يكاد") في وصن (9)

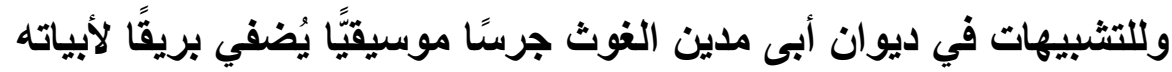

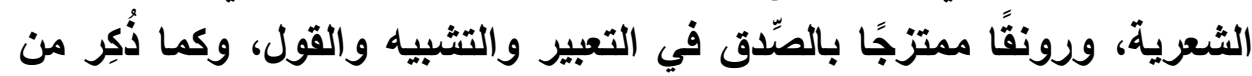

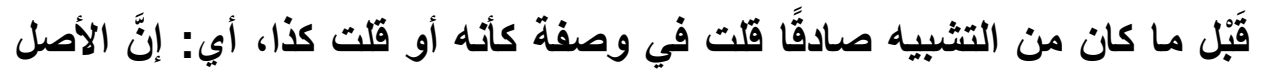

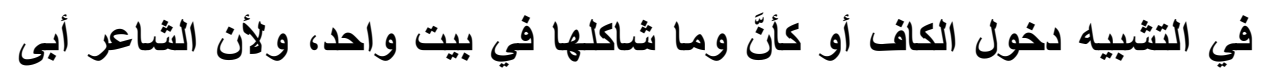

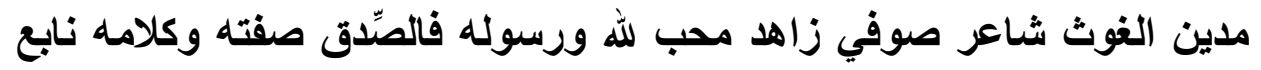

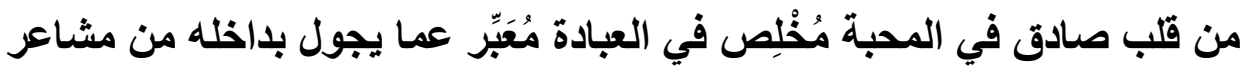
جيّاثه، لذلك كاتت تثبيهاته بين الكاف وكأن وكما ومن أمثلة

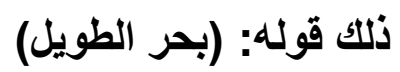

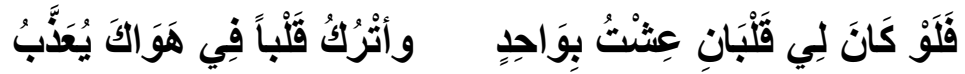

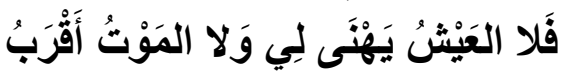

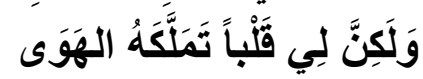

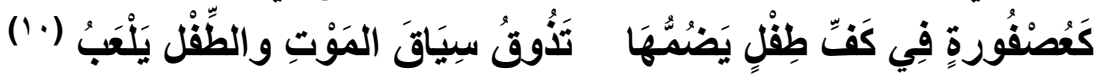

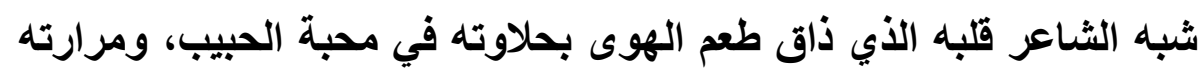

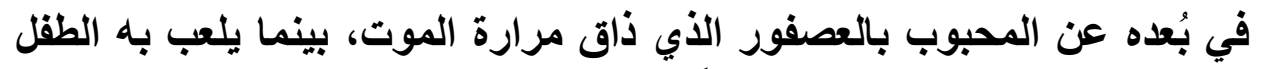

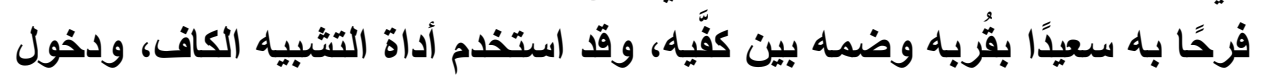

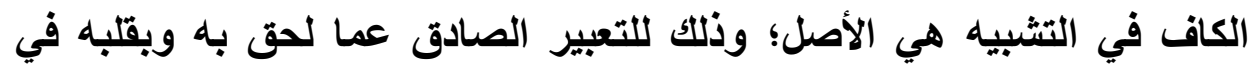

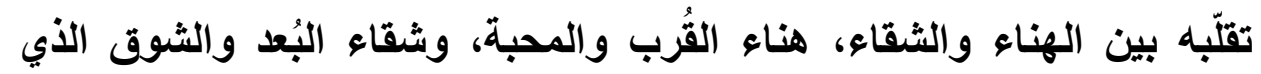

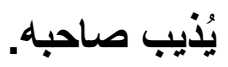
وقوله: (بحر الخفيف) و والبه

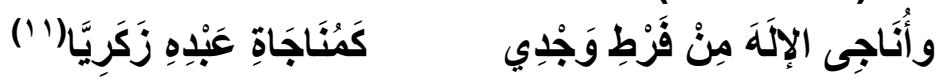

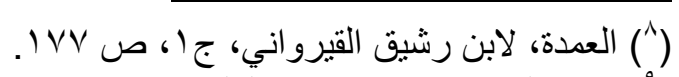

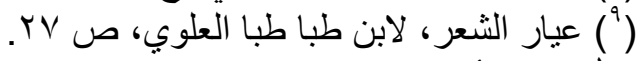

$$
\begin{aligned}
& \text { (') (") }
\end{aligned}
$$

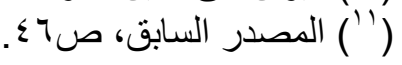


ليس للإنسان إلا الله فهو المُنجى من المهالك، الرازق بغير حساب، الهادي

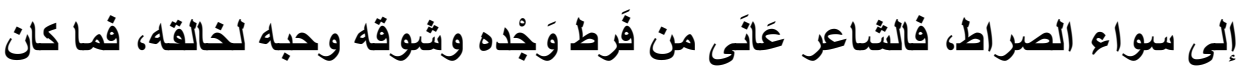

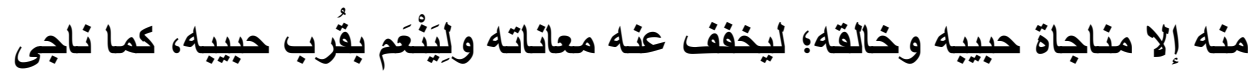

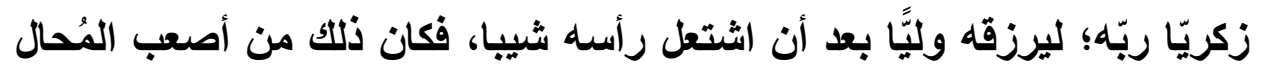

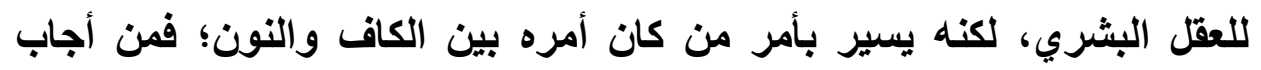

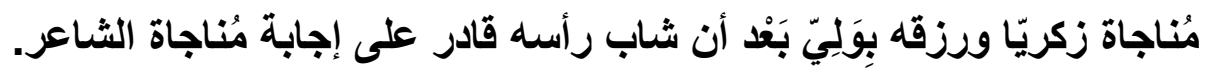
وقوله: (بحر الطويل)

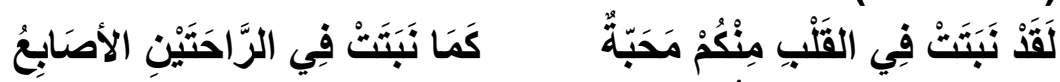

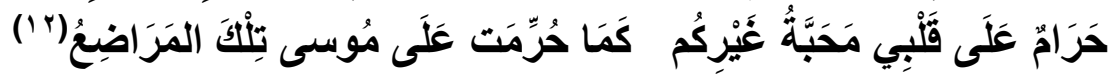

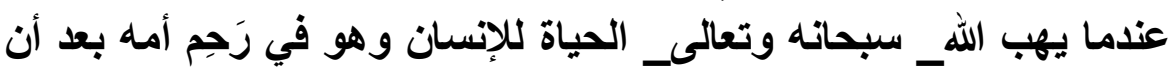

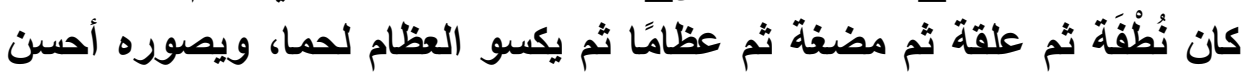

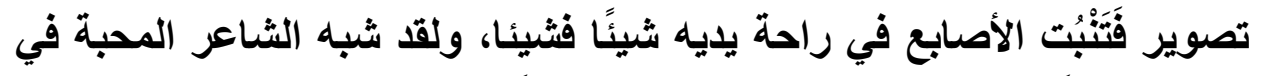

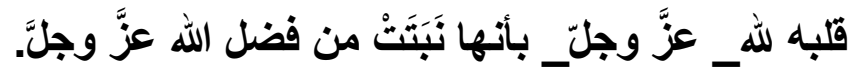

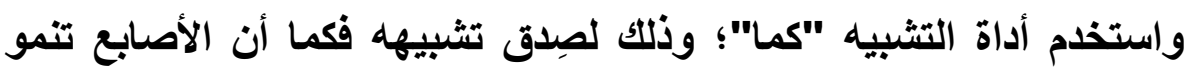

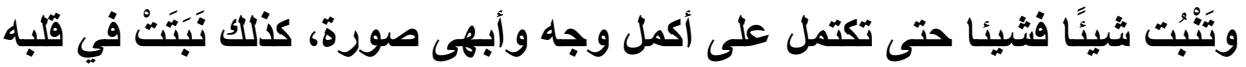

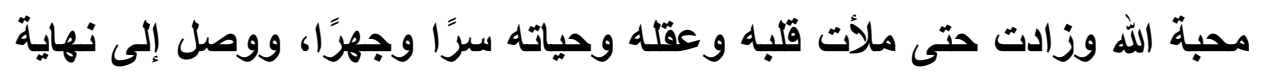

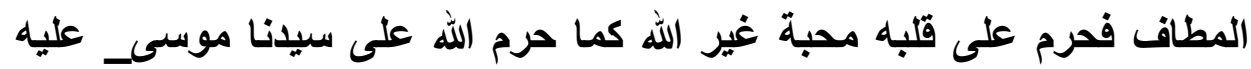

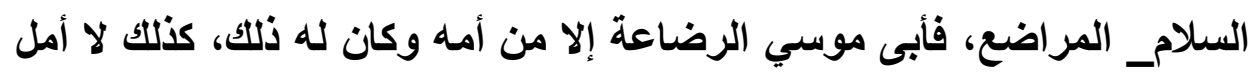

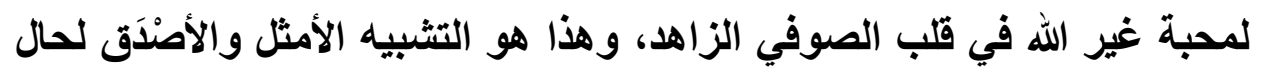
شاعر الحب الإلهي. وقولهة: (بحر البسيط)

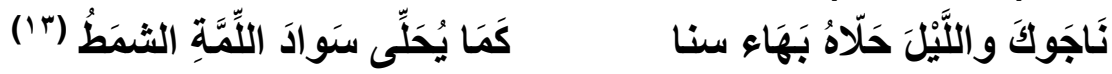

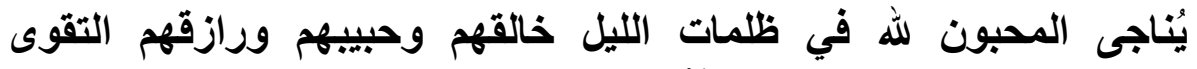

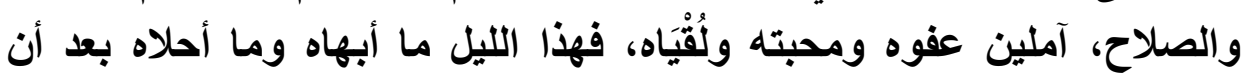

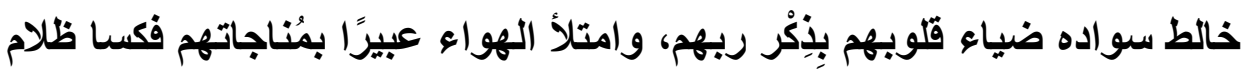

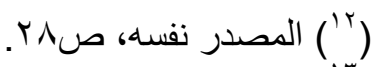

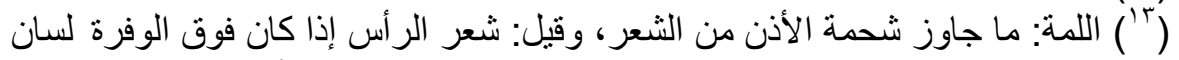

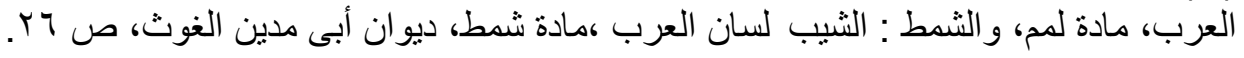


الليل سحابة من نور أفواههم ذِكْرًا لربهم، فهذه الخطوط البيضاء التي تُلوّرّن

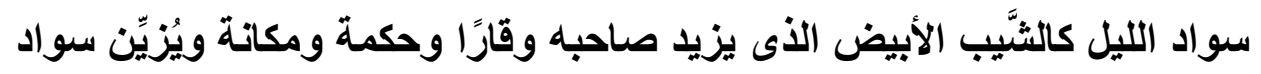
رأسه بثَيْب أبيض يكسوه.

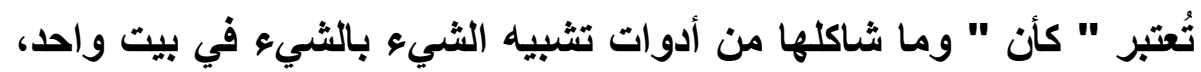

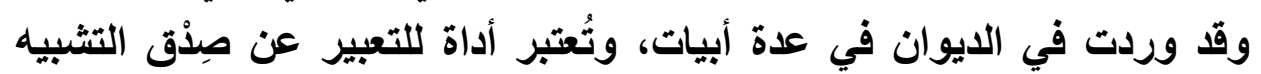

وَكَأَنَكُمْ فِي بِقَاع الأرْضِ أمْطَرُ

وذلك أمثال قوله: (بحر الكامل)

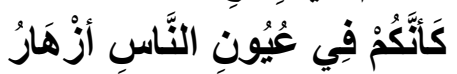

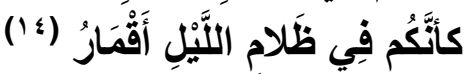

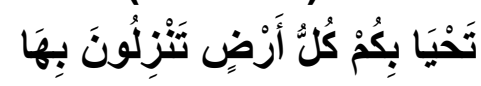

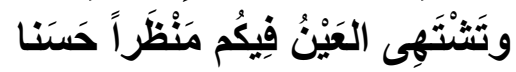

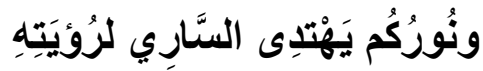

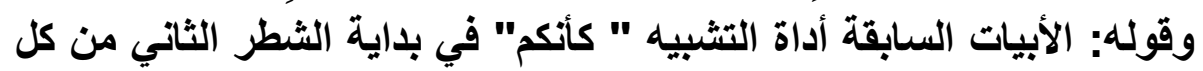

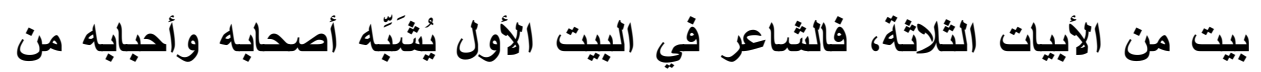

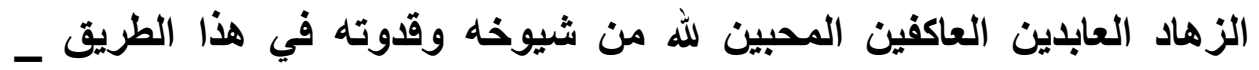

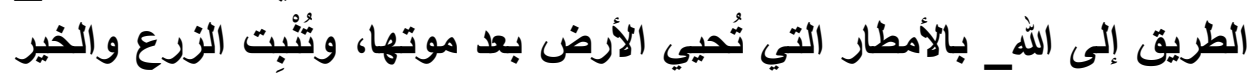

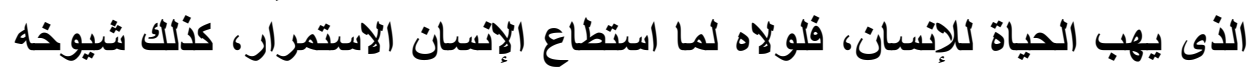

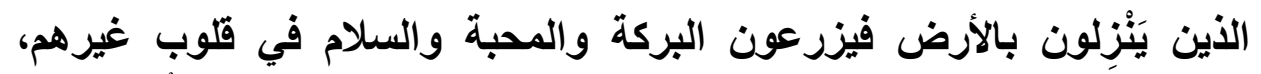

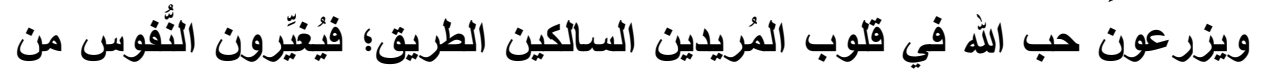

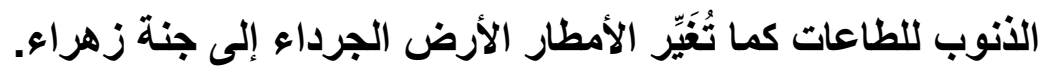

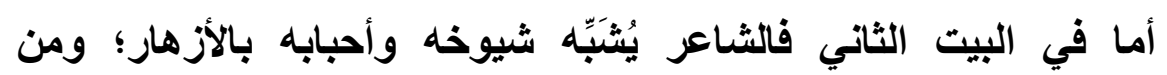

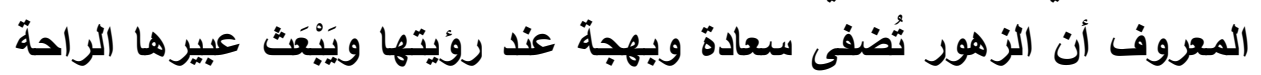

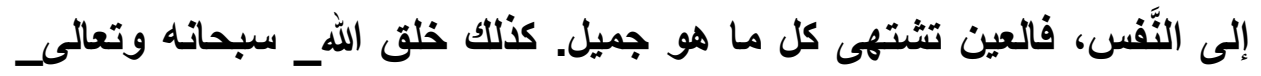

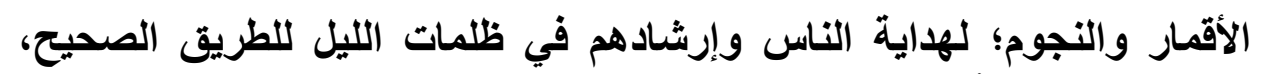

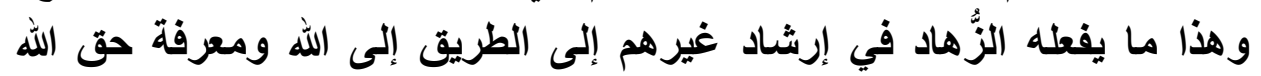

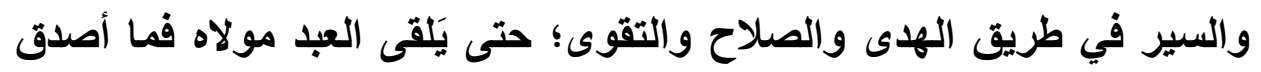
تثبيهاته وما أجمل تعبيراته و وعبار اتها وقوله: (بحر البسيط)

كأنَّها مَا تَحَلَّتَ بالنَّبَاتِ قَطُ

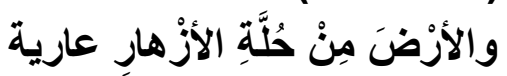

(') (المصدر السابق، ص 19. 


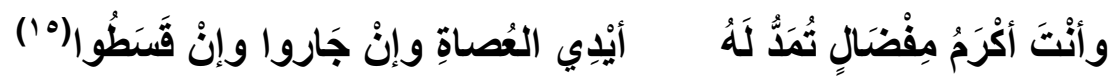

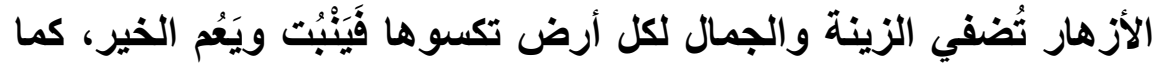

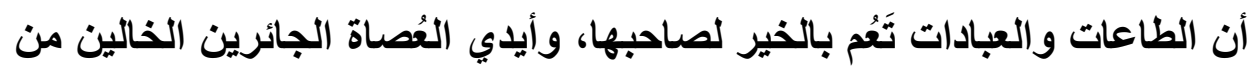

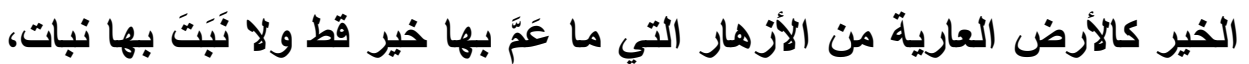

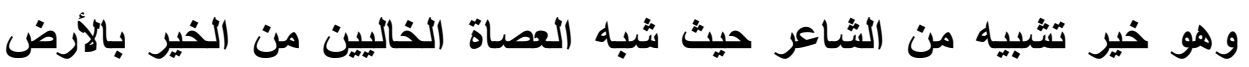
العارية من الزهر والنبات.

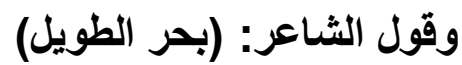

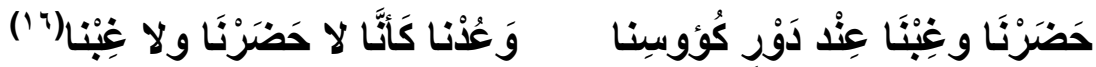

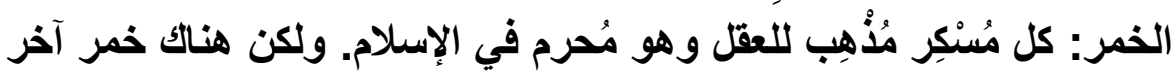

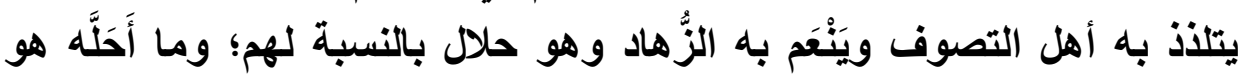

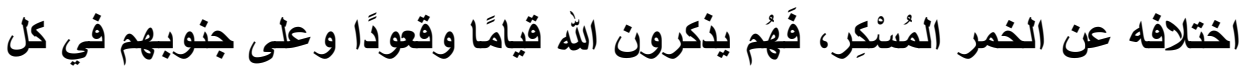
وقت ومكان، وما يزالون يذكرونه حتى يذهب عقلهم وتسمو روحهم عن ئن

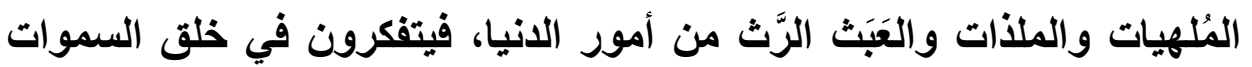

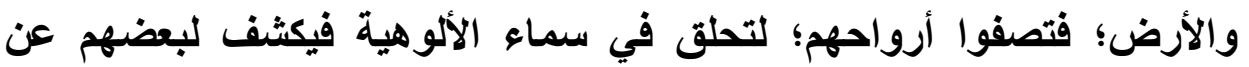

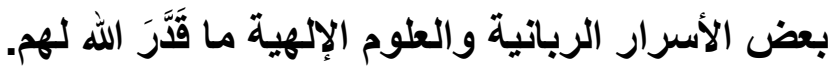

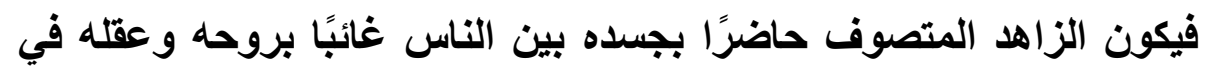

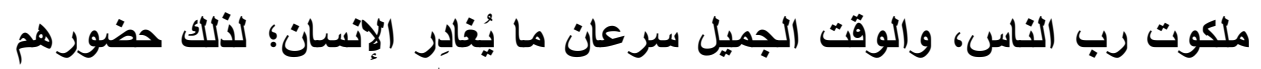

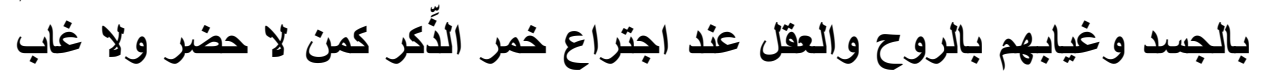
فهم الحاضرون الغائبون. 


\section{ة1}

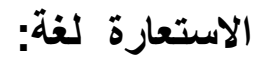

"عير: يقال للموضع الذي لا خير فيه: ( وهو كجوفِ العَيْر ) وهو الحمار

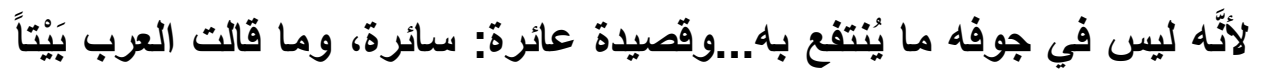

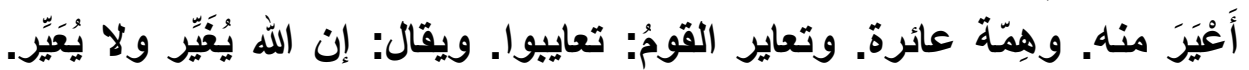

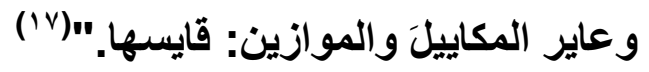
الاستعارة اصطلاحا:

"ومن سنن العرب الاستعارة وهو أن يضعوا الكلمة للشيء مستعارة من

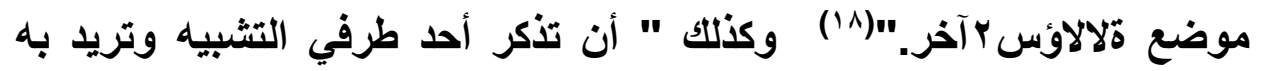
الطرف الآخر، مدعيًا دخول المشبه في جنس المشبه بهاه، دالًا على ذلك بإثباتك

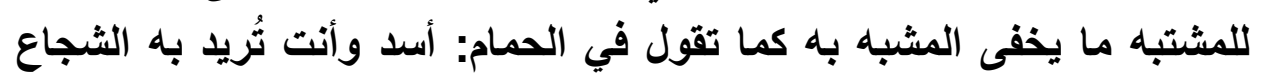

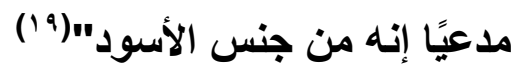

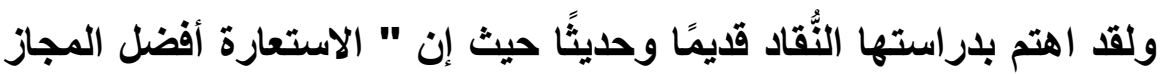
وأول أبواب البديع وليس في حلى الثعر أعجب منها وهي من محاسن الكلام إذا وإنائا

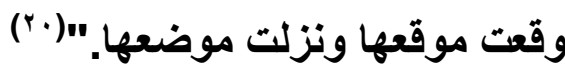

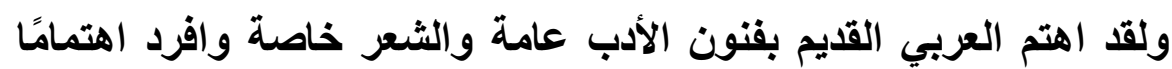

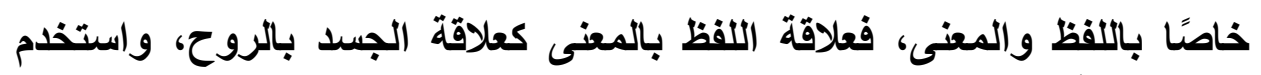
العرب الفاظًا كثيرة للمعنى الواحد لألك تعد " الاستعارة من اتساعهم في الكلام اقتدارًا وداله ليس ضرورة، لأن الفاظ العرب أكثر من معانيهم وليس ذلك في لغة الته

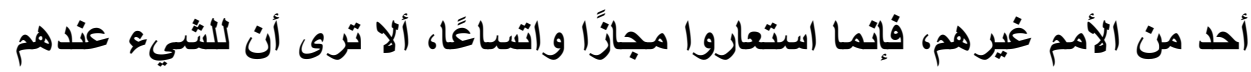

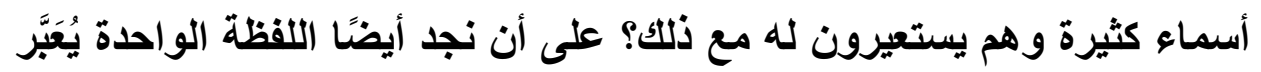
بها عن معان كثيرة نحو " العين " التي تكون جارحة وتكون الماء وتكون لهن أجناء

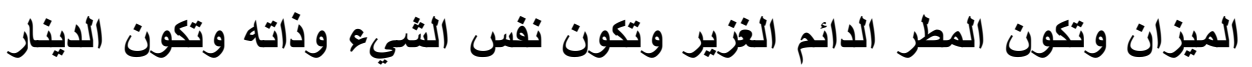

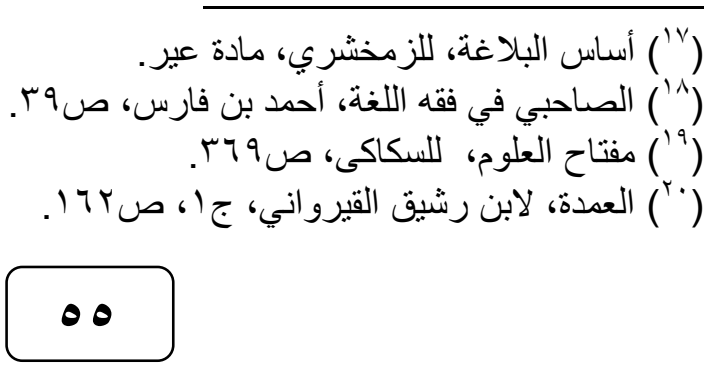


وما أشبه ذلك كثير وليس هذا من ضيق اللفظ عليهم، ولكنه مع الرغبة في

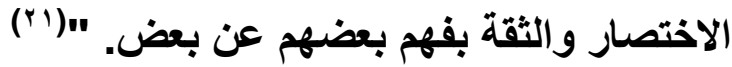
وهذا إن دلَّ على شيء إنما يدل على فصاحة العرب ومقدرتهم على الكلام العلام البيان والبلاغة وسرعة البديهة والفهم والفطنة، وتمكنهم من لغتهم بما تحويه

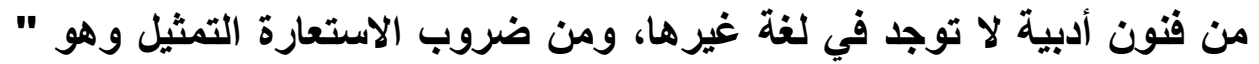

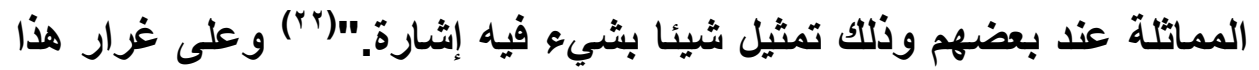
التعريف يمكن القول بأن التمثيل والاستعارة من التشبيه "إلا إنهما بغير أداته

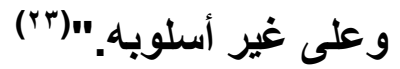
" ويسمى المشبه به سواء كان هو المذكور أو المتروك مستعارًا منه واسمه

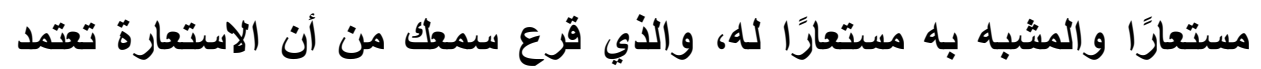

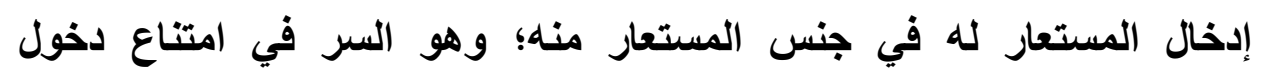

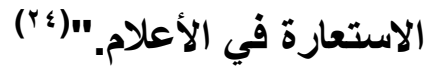

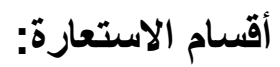

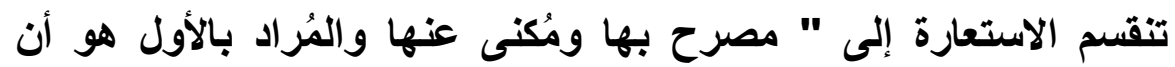

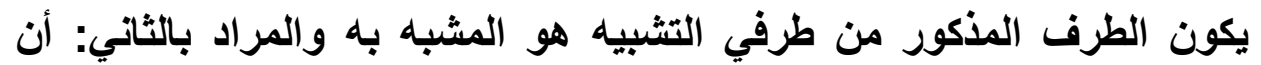
يكون الطرف المذكور هو المشبه، والمصرح بها تتقسم إلى تحقيقية وتخليلة والمراد بالتحقيقية: أن يكون المشبه المتروك شيئًا متحققًا إما حسيًّا وإما عقليًّا.

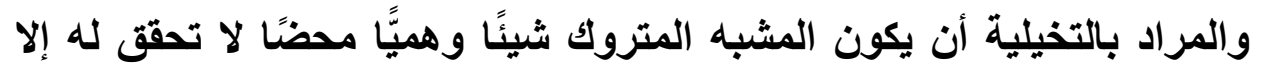
في مجرد الوهم، ثم تنقسم كل واحدة منهما إلى قطعية وهي أن يكون المشبيه

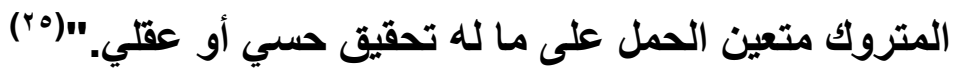

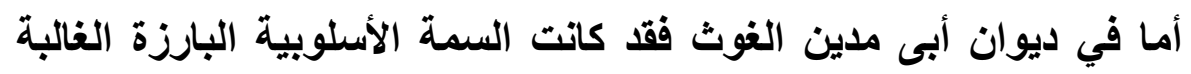

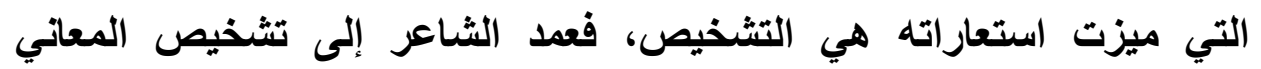
ومظاهر البيئة الجامدة من حوله، ولقد كان توظيفه لظاهرة التثخيص في

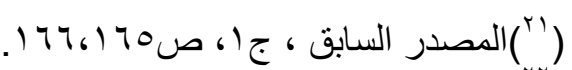

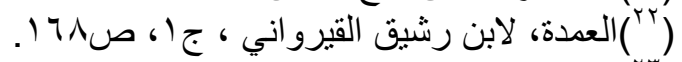

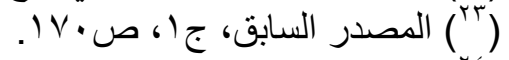

$$
\begin{aligned}
& \text { ( }
\end{aligned}
$$

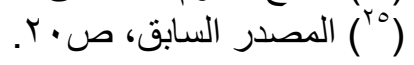


ديوانه توظيفًا موفقًا نابعًا من صِدْق مشاعره وأحاسيسه. ومن أمثال توظيفه

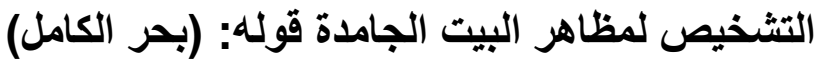

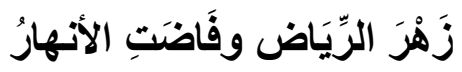

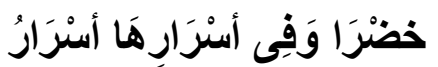

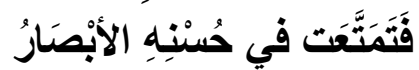

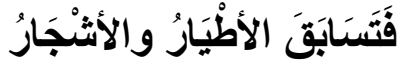

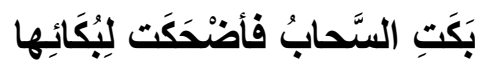

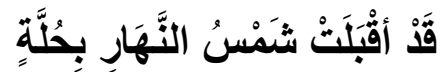

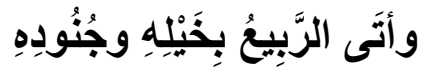

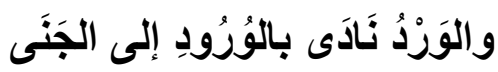

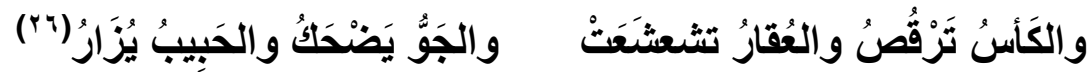
أكثر الثاعر من سمة التشخيص في هذه الأبيات فقد صور السحاب بشخص

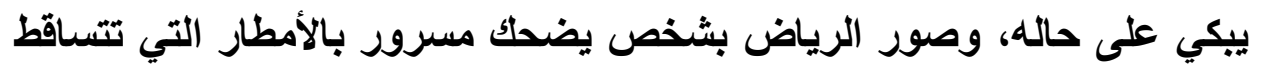
من دمع السحاب، كما صور الشمس التي تسطع في النهار وتملأ الكون نورًا

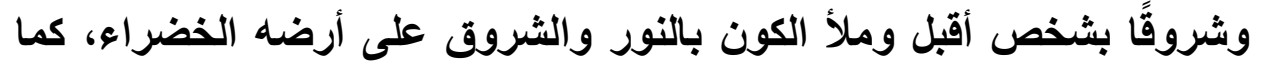

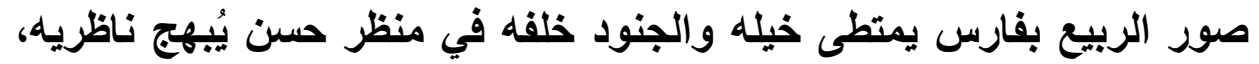

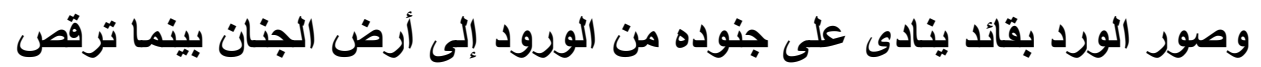
الكاس كأنها شخص فرح سعيد في وسط ضحكات الجو عند زئل زيارة محبوديه. كما كان للاهر حظ في استعارته التشخيصية حيث قال: (بحر الطويل)

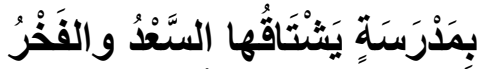

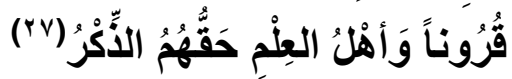

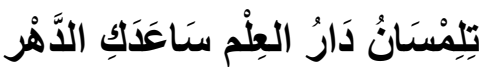

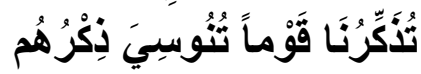

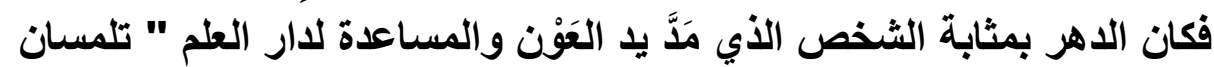

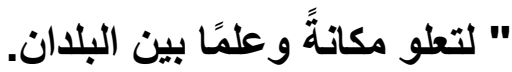

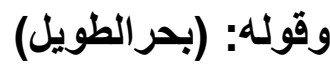

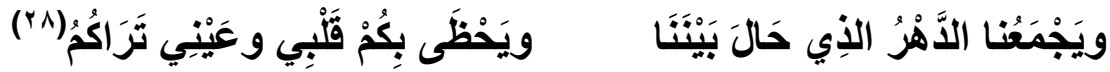
والأَّر بمثابة الثخص الإي يجمع الحبيب بحبيبه بعد أن حال بينهما، وكان بينان حاجزًا يحول بين اللقاء، كذلك كان للظواهر الطبيعية الجامدة في البيئة المحيطة ولغيرها من جماد مرتبط بالإنسان أثر في مقارنته التثخيصية فقوله: (بحر لهره 


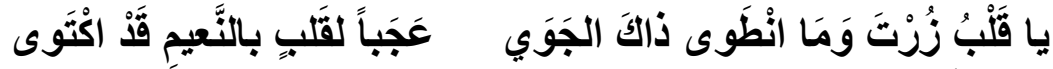

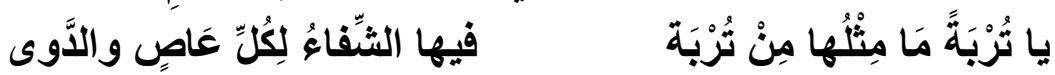

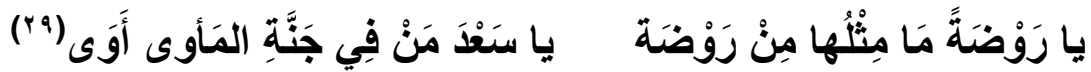

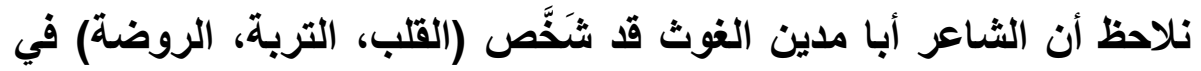

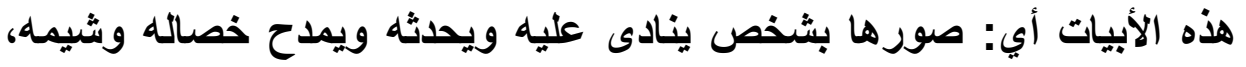

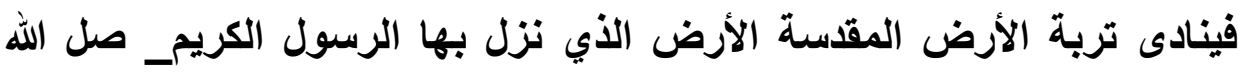

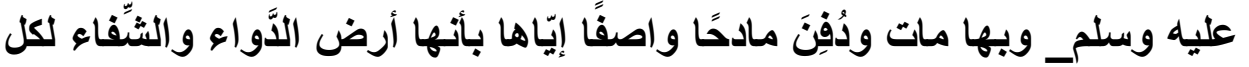
عاص كذا فعل مع الروضة الثريفة.

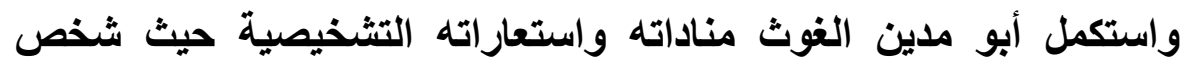

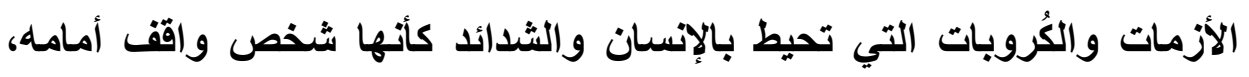

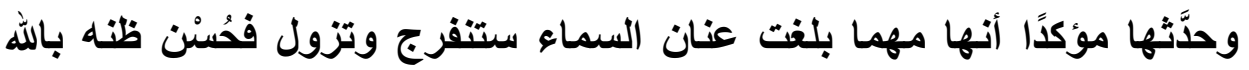

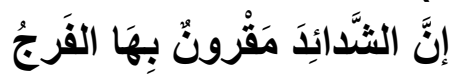

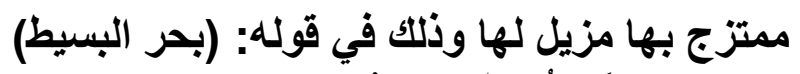

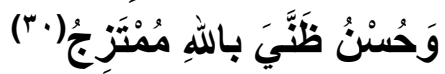

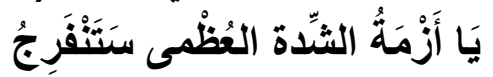

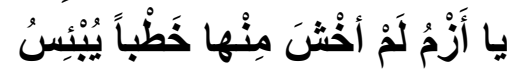

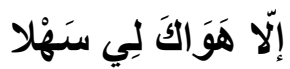

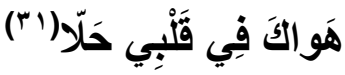

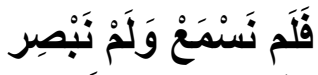

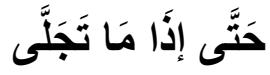

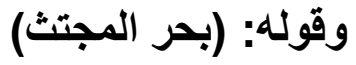

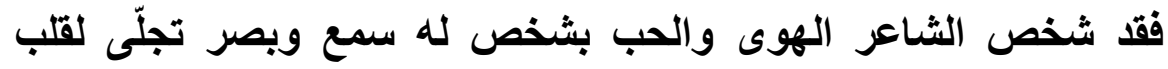
صاحبه، كذلك الأمر فقد شخص الهوى في موضع الهُ آخر من ديوانه في قوله: (بحر الطويل)

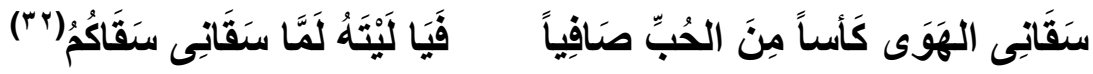

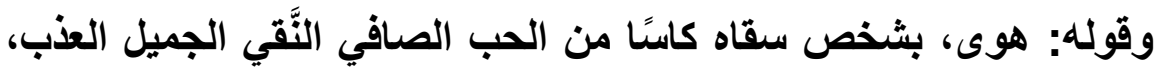

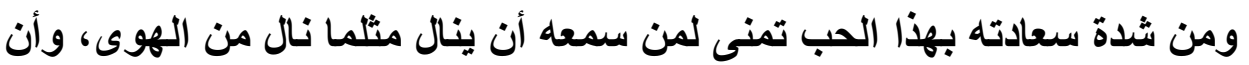
يَسقى الهوى غيره من الناس كؤوس المحبة والصَّبَابة والهوى.

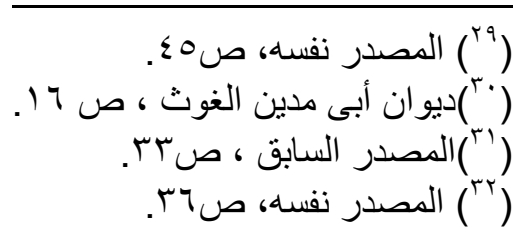

०ᄉ 


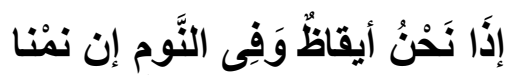

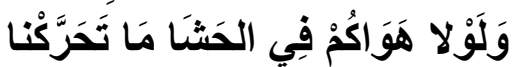

وقوله: (بحر الطويل)

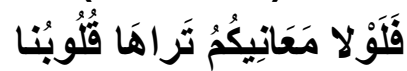

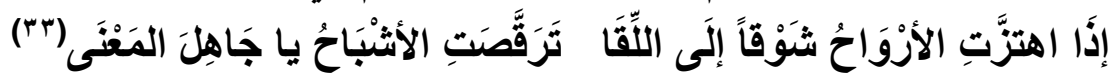

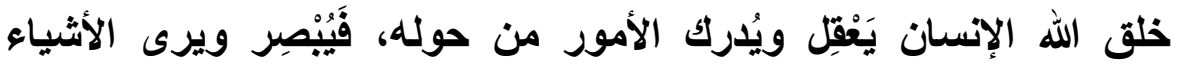

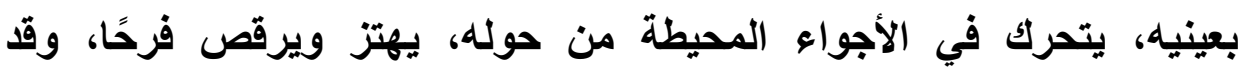
استثعر الثاعر هذه الصفات لغير صاحبها الإنسان فجعل القلب إنسان يرى فئه

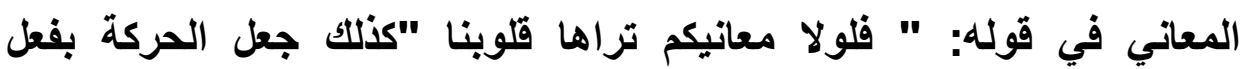

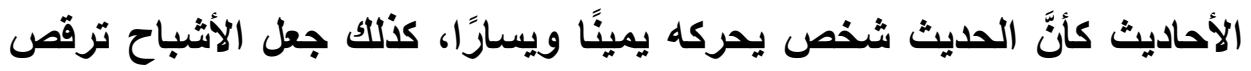

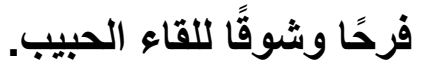
وقوله:

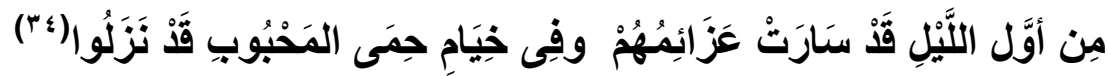

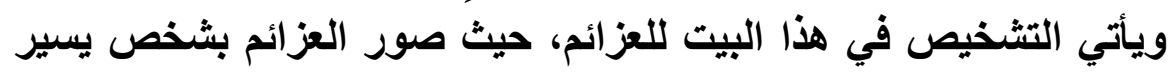

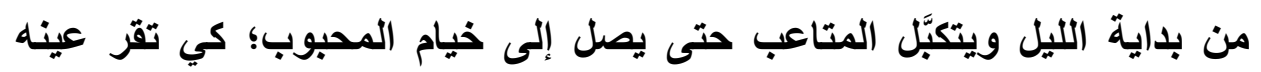
بروية محبوبه وما زال التثخيص يحتل الصدارة في لئي قوله: (بحر الكامل)

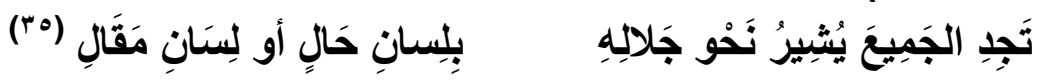

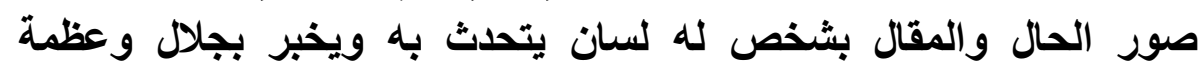

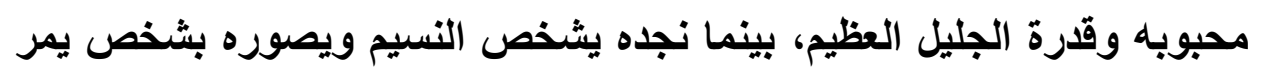

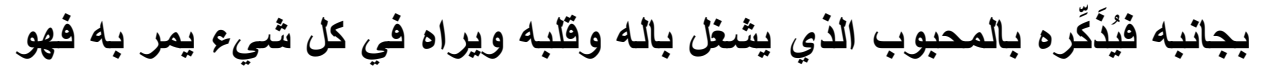

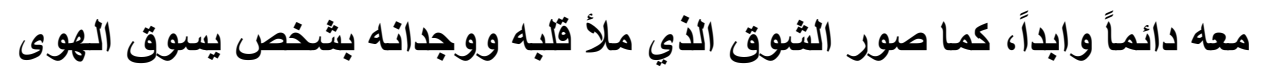

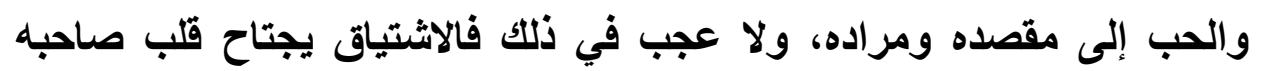

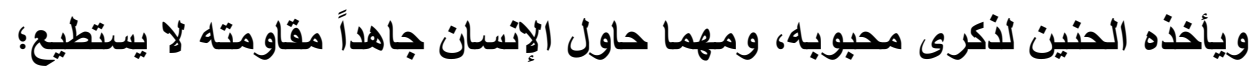

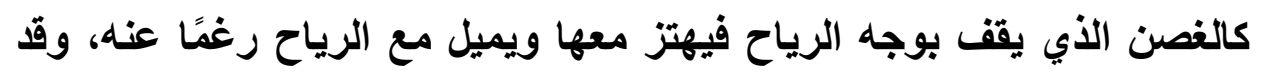
شَخَّص الثَاعر ذلك في قوله: (بحر الطويل)

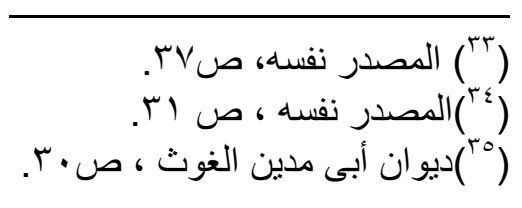


وَيُطْرِيُني الحَادِي إذَا بِاسنْمِها غَنَّى

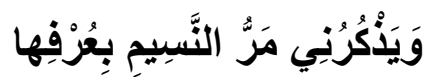

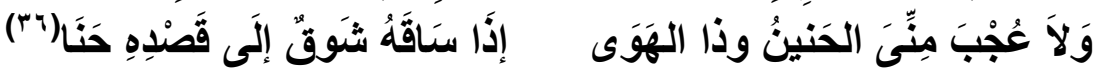
كذلك شَخَّص القلوب فجعلها تهتز من شدة الفرح والسرور عند الاستماع للمحبوب؛ فقرب القلب من محبوبه يجعله يقفز ويهتز من السعادة والبهجة . وذلك في قوله: (بحر الطويل)

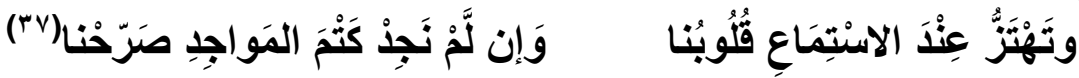
فقد جمع بين التثخيص والتجسيد في عدة أبيات منها:

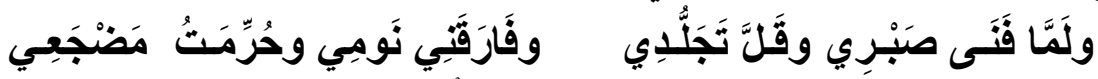

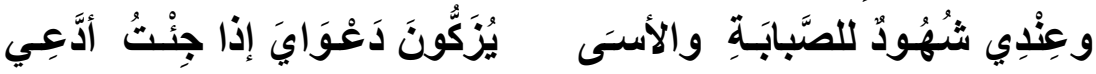

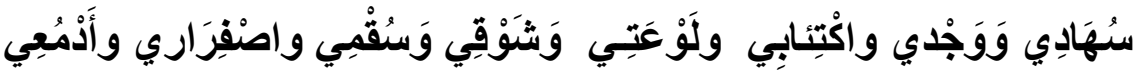

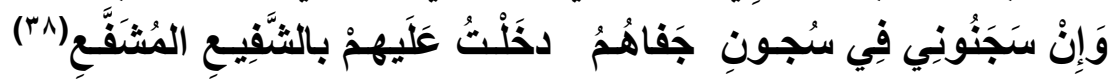

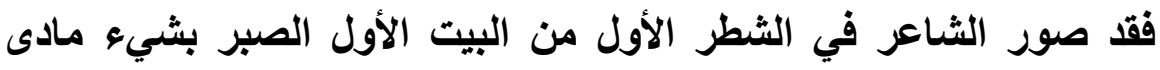

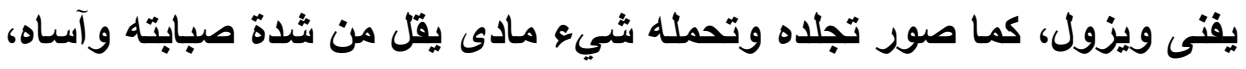

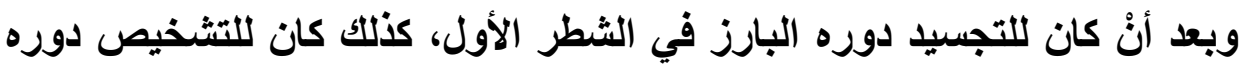

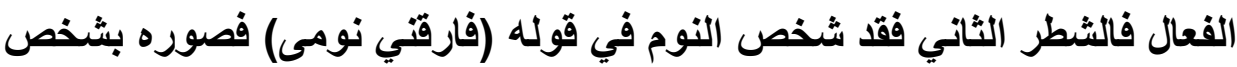

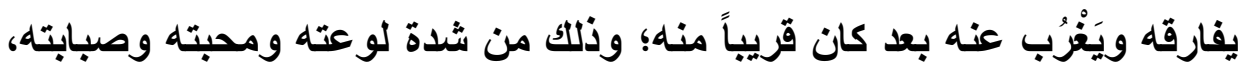
فالنوم سلطان يظلب صاحبه ولكن هذا السلطان خسر معركته وفارق صنان صاحبه

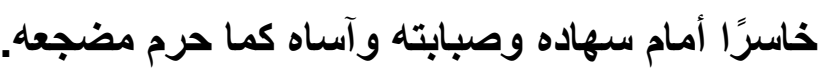

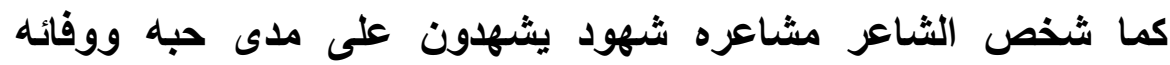

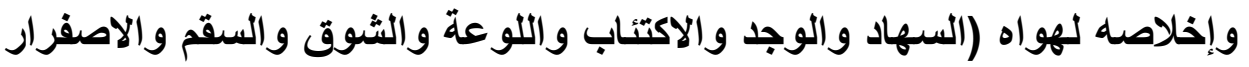

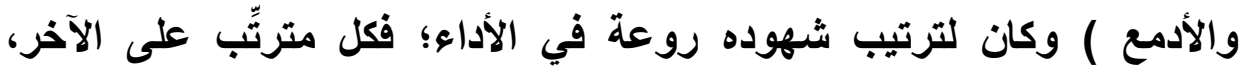

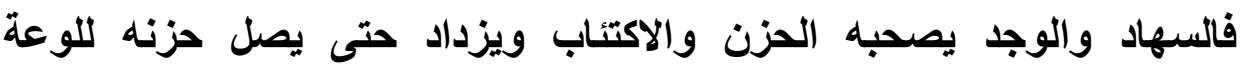

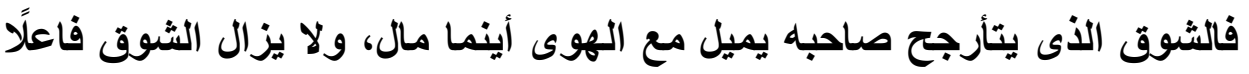
به ذلك حتى يسقم ويمرض من شدة شوقه لمحبوبه الذى يرجو لُقياه حتى تقر عيناه.

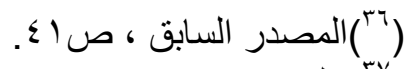

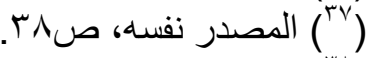

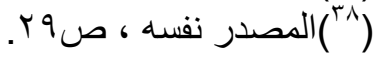


وسقم الهوى يأتي بالاصفرار في الوجه؛ فالمريض نرى الإجهاد والتعب

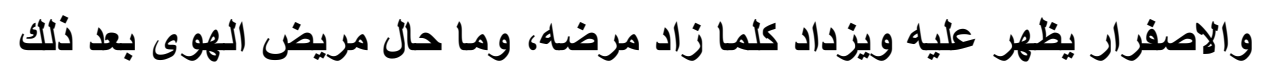

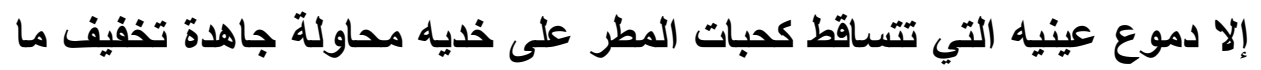

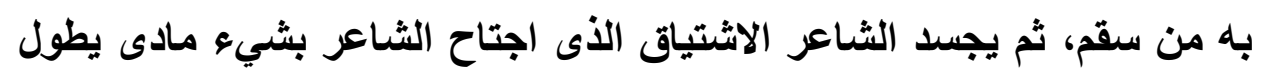

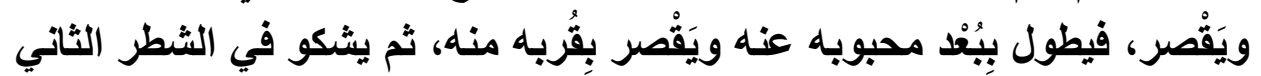

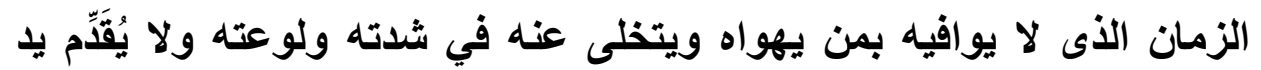
العون والمدد له كما يفعل الصديق المخلص لصديقه وذلك في قوله: (بحر (لبسيط )

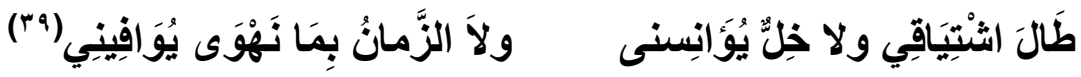

$$
\text { وقوله: (بحر الطويل) }
$$

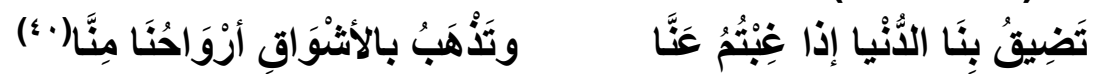

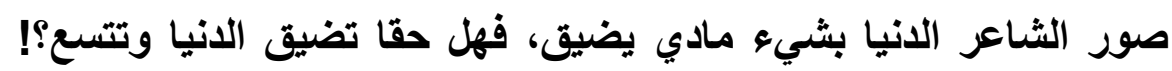

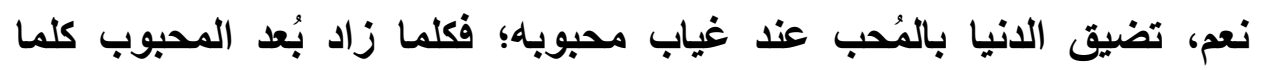

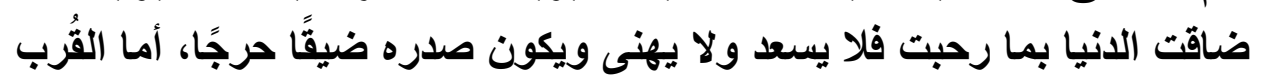

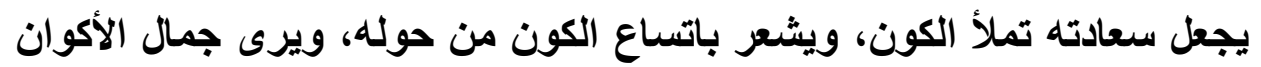

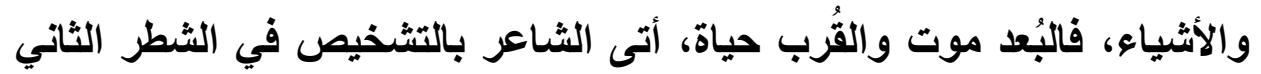

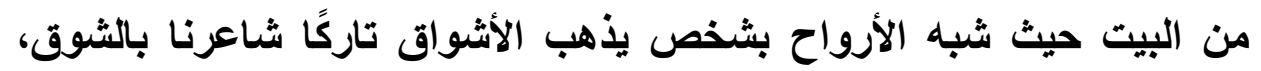

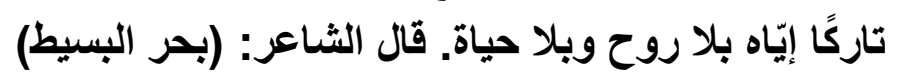

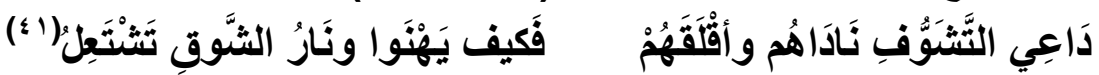
نار الشوق تشكل صورة تشبيهية جميلة، حيث صور الشوق بشيع مادي وني

يشتعل نارًا وذلك من باب التجسيد. وقوله: (بحر الطويل)

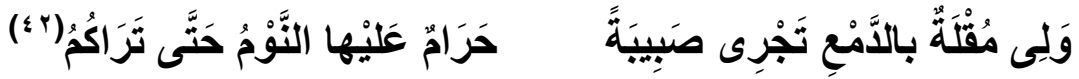

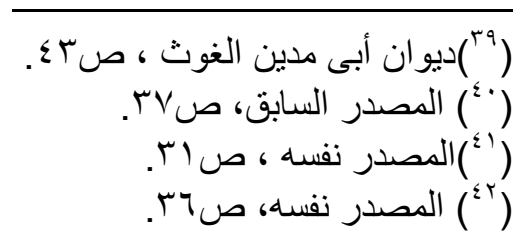


صور الثاعر مقلة العين بسفينة تجرى بدمع العين من شدة الثوق

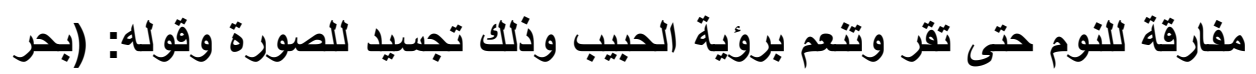

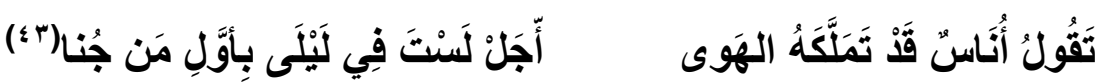
(الطويل)

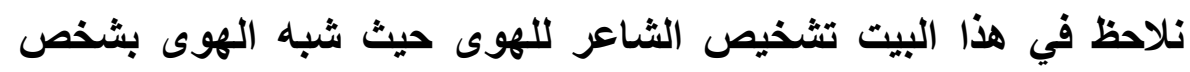

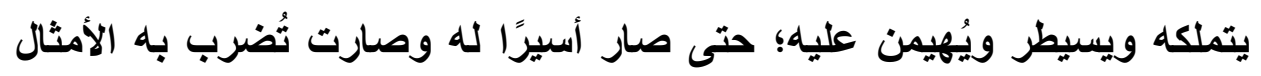

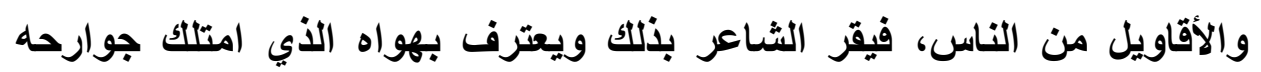
ويبرر ذلك بأنه ليس بأول من أحب.

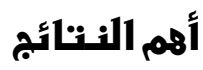

(1)(الصورة الثعرية في ديوان أبى مدن الغوث لها دلالات أثرت المعنى وزادته

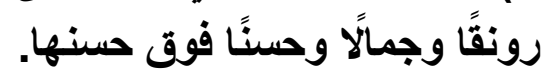

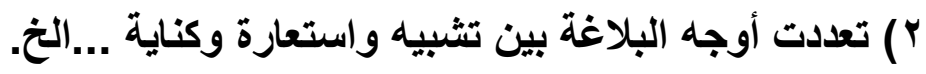

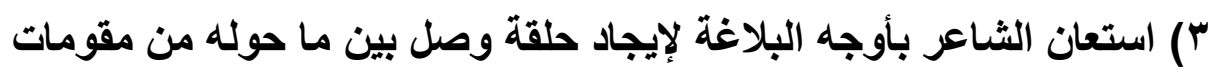

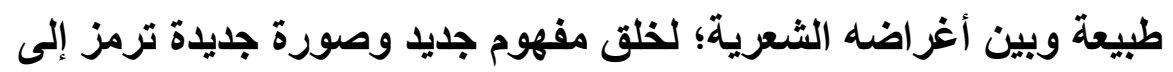

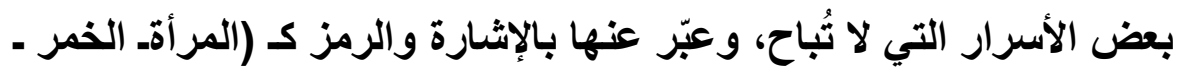
(الكاس...الخ)

\section{المصادر والمراهير}

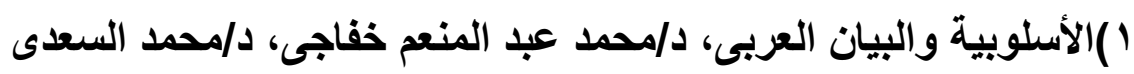

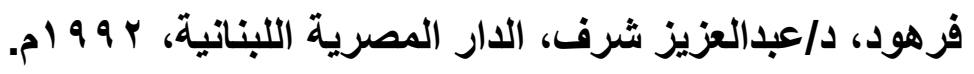

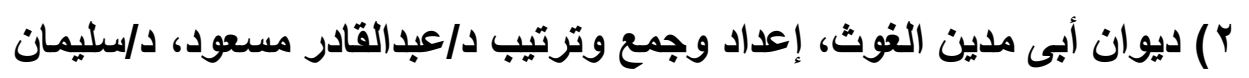

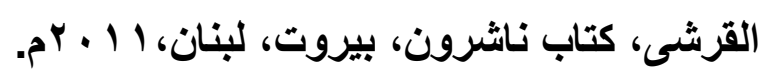

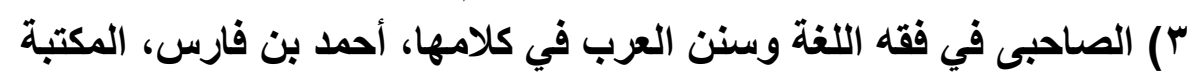

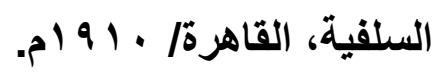

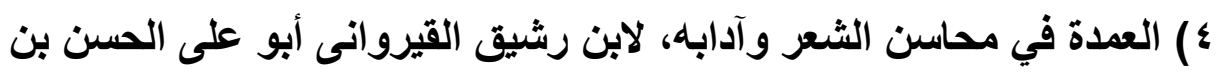

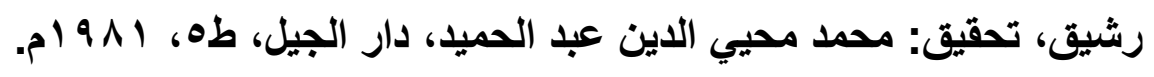

(") 


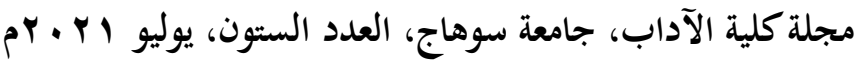

•) معجم أساس البلاغة، أبى القاسم جار الله محمود بن عمر بن أحمد

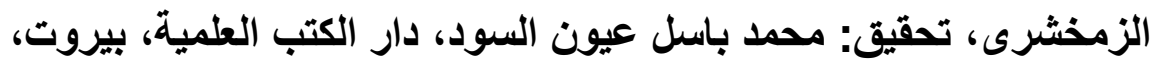

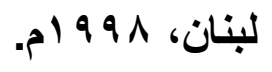

\) مفتاح العلوم، يوسف بن أبى بكر بن محمد بن على السكاكى، تحقيق: نعيم

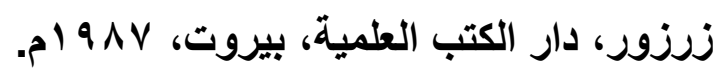

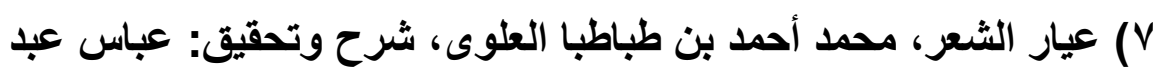

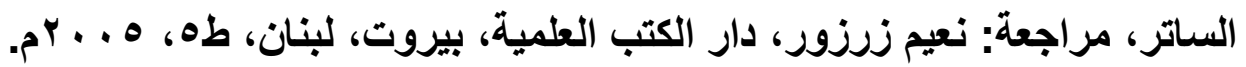


